\title{
3. Experimental design: scaling up in time and space, and its statistical considerations
}

Jens-Arne Subke, Andreas Heinemeyer and Markus Reichstein

3.1 INTRODUCTION

Accurate measurement of the soil $\mathrm{CO}_{2}$ efflux is critical for the assessment of the carbon budget of terrestria ecosystems, since it is the main pathway for assimilated carbon to return to the atmosphere, and only small changes in the soil $\mathrm{CO}_{2}$ efflux rate might have important implications on the net ecosystem carbon balance. Due to this central role in the terrestrial carbon cycle, soil $\mathrm{CO}_{2}$ efflux has been measured throughout all biomes, and covering all principal vegetation types. Using simplified regressions of soil $\mathrm{CO}_{2}$ efflux measurements reported in the scientific literature, the total surements amount ofcerbo been estimated at approximately $68-80 \mathrm{Pg}(1995$; Raic et al., 2002), representing the second largest carbon flu between ecosystems and the atmosphere. This amoun is more than ten times the current rate of fossil fue combustion and indicates that each year around $10 \%$ of the atmosphere's $\mathrm{CO}_{2}$ cycles through the soil (Prentice et al., 2001). Thus, even a small change in soil respiration could significantly intensify, or mitigate, current atmospheric increases of $\mathrm{CO}_{2}$, with potential feedbacks to climate change. In foct, soils store more than twice to climate che much carbon globally han the atmosphere (Bolin, 2000) and consequently contain a large long-term potentia for the carbon cycle climate feedback. Applying results from small-scale experiments to larger areas is necessary in order to understand the potential role of soils in sequestering or releasing carbon under changed climatic conditions, and to inform management and policy makers about likely consequences of land-use changes on carbon fluxes and stocks in specific regions. As in the example of the global estimate mentioned above, there is inevitably a need to estimate the soil $\mathrm{CO}_{2}$ efflux over vast areas that it is impossible to cover appropriately by actual measurements, and for time scales beyond the scope of measured data, particularly where future predictions are required.

Scaling up from sparse and infrequent measurements to the level of, for example, catchment, region or even continental or global scales, bears a considerable degree of uncertainty, making such extrapolations difficult. The scope of this chapter is to introduce a range of requirements that are critical to facilitate meaningful extrapolation of results observed on small scales to allow making estimates of soil $\mathrm{CO}_{2}$ efflux over larger areas and longer time scales. The aim is to provide enera lover in order to enable the reade to desin a a suitable measuring strategy towards such

Measuring techniques can be broadly divided into (1) chamber-based, (2) soil profile and (3) eddy covariance approaches. Chamber-based measurements provide by far the majority of published results, and the general considerations of heterogeneity are valid for all measuring approaches. We therefore concentrate on chamber-based measurements to illustrate experimental designs for dealing with natural variations in soil $\mathrm{CO}_{2}$ fflux. Soil profile methods allow a verticl resolution the of erovicon sols by roots and contributions to the heterotrophic flux component for different soil depths. However, soil profiles inherently create considerable disturbance both during installation and sampling (Fang and Moncrieff, 1998) and are difficult to replicate within plots. For successful applications of this technique, please refer to Tang $e t a l$. (2003), Liang et al. (2004) and Davidson et al. (2006) Eddy covariance has been applied to measure soil surface $\mathrm{CO}_{2}$ flux with some success (see e. Iaw et at, 1999; Ja Subke and Tenhunen, 2004). This technique has the advantage of causing no disturbance to the soil, but i is restricted to conditions of sufficient atmospheric turbulence, and homogeneity of the surface in the up-win fetch. However, eddy covariance is much less suited for measuring under a closed forest canopy or in complex terrains.

Although laboratory incubations are important in Alesing cerlin hypotheses (e.g. temperature sen-

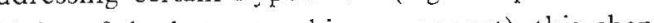
sivity of the hecerotophic comp. does not provide in-depth detail on this topic but concentrates on the relative strengths and limitations of some laboratory-based approaches in the context of flux measurements. References given in that section and those by Reichstein and Janssens in Chapter 11 of this book) are intended to guide the reader to look up individual studies on technical issues. Soil $\mathrm{CO}_{2}$ efflux measuring equipment and auxiliary measurements at merimental sites have been addressed in the previous experim, a the actol methods of

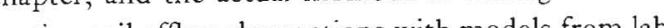
preting soil eflax observations with models from laboratory to global scales are covered in Chapter 11 . Here we point out some further measurement considerations in relation to capturing temporal variability accurately. Finally, we provide a logical framework of how to design and perform statistically sound experiments for testing hypotheses.

\subsection{SP ITIAL IND TEMPORAL}

VARIABILITY

3.2.1 Sources of variability

Soil $\mathrm{CO}_{2}$ efflux is the sum of respiratory activity from a variety of sources. Mineralization of carbon from both fresh litter and older soil organic matter (SOM) through soil-dwelling animals, fungi and bacteria comprise the heterotrophic flux contributions. The separation of this flux from autotrophic sources is ambiguous (see Moyano et al., Chapter 7), as definition in the literature differ according to a classification by in the literature differ accordig a a chection the source of carbon being respired and the fraction of soil biota in which respiration actually occurs. Growth and maintenance respiration by plant roots represents the true respiration by autotrophs, but mineralization of carbon contained in compounds secreted by living roots (exudations, mucilage or sloughed root cap cells) by soil bacteria or fungi form a grey area in the categorization of flux origin (see e.g. Kuzyakoy, 2006a, b and
Hërerg et al., 2006 for a recent debate on the issue of separating these flux contributions). For the purpose of parating the mex contributions). For the purpose this chapter, we consider he portion or soil $\mathrm{CO}_{2}$ eflux caused by the input of carbon from roots as autotrophic respiration. It therefore includes respiration by mycorrhizal fungi, which obtain substrate for their metabolism nearly exclusively from their hosts' roots, and that of al other soil microbes metabolizing recent plant-derived carbon (such as usage of root exudates). In addition to these biotic flux sources, soils may have a varying degree cin of inorganic fluxes through the weathering of
contained in soil and underlying geology.

Soils form over periods of hundreds to thousands of ars, and their structure and carbon content is mainly a result of the geologic parent material (e.g. bed-rock of varying weatherability, or mineral deposits such as sands or clays), geomorphological conditions (e.g. slope and aspect of the soil surface), local climate and vegetation cover (Jenny, 1980). It is important to note that in particular climate and vegetation cover are not constan site factors but may vary considerably during pedogeTes. Thus orgaic carbon within the soil represents a mix. Thus or ages, ranging from very recently fixed lita mix cabon to he rifed materiats literally thousends of vers ald This mix me represents not only pesent years old. This mikture represents not only pesent site conditions but also a long legacy of previous biotic and abiotic influences. Physical structure and chemical composition of the soil is therefore also linked to the diversity of organisms to which the soil has been a habitat over these periods, with significant implications for the physical distribution of organic matter and cycling of nutrients, which in turn impacts on the vegetation cover above ground (see Chapters 9 and 10).

Consequently, in a physically complex structure such as soil, sources of carbon substrates (for all types of respiration) are not distributed homogeneously, and their availability at any given place may also change with time. Nunan et al. (2002) observed different spaiial structures in the distribution of soil microbes, which were closely linked to pore space within the soil. While popsil distributions showed a pattern on the micrometre scale in the subsoil an additional but separate cento metre scale could be observed.

The abiotic soil environment (e.. . soil temperature, water content, $\mathrm{CO}_{2}$ and $\mathrm{O}_{2}$ concentrations) strongly influences the rate at which $\mathrm{CO}_{2}$ mineralization from different sources accurs. In the literature most attention has been attributed towards soil temperature and 
moisture as they impact strongly on both autotrophic and heterotrophic activity. For example, soil temperature fluctuation at the soil surface propagates into soil depths both with dampened amplitude and increasin time lag, which has to be considered if a significant portion of the surface $\mathrm{CO}_{2}$ efflux originates from a lower ailure fle (see also Che ature fluctuations are, in turn, strongly dependent on vegetation cover and its exposure throughout daily and seasonal cycles. Irregular canopies, for example, result in considerable differences of incident light at ground level with potentially significant consequences for soil tempcratures. Soil moisture conditions may also differ at a small scale, as canopy throughfall often consistently differs in space due to canopy structure or patchiness of ground vegetation cover. Under well developed reo ular canopies with high leaf area index (ILII) values, by contrast soil temperature and her (Le al) likety by contrast, soltempere be more homogneous, so tha differences in soil $\mathrm{CO}_{2}$ efflux are likely to be smaller.

There are, however, other important biotic factors, which, although mostly overlooked, should be considered when measuring and modelling soil $\mathrm{CO}_{2}$ efflux, such as the distribution of live roots and soil fungi, both showing considerable spatial and temporal variations at the plot scale. Root density is affected by soil structurc (c.g. bulk density and rock content) and soil depth, and the distribution of nutrients and warer avilabiland the distion availabil-

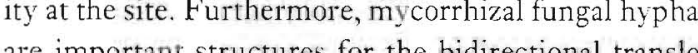
are important structures for the bidirectional translocation of nutrients from local patches ('hot spots') to roots, and of carbon from the host plant to the fungus for its growth and metabolic requirements (Smith and Read, 1997). Naturally, this flow of carbon from plants to symbiotic fungi is directly linked to the rate of assimilation by the canopy, and as such will show seasonality due to canopy phenological changes. There fore, the degree to which biotic conditions differ within a site is strongly dependent on local abiotic condivions, smalls in top small-scalc top do is also important to consider the degree of heterogeneity throughout the phenological cycle, as a single are survey may not capture the variation of this biotic flux contribution accurately. As the autotrophic flux component of the biotic flux might be largely independent of the commonly observed changes in soil temperature, due to temperature acclimation of root respiration (Atkin et al., 2000) or mycorrhizal hyphae (Heinemeyer

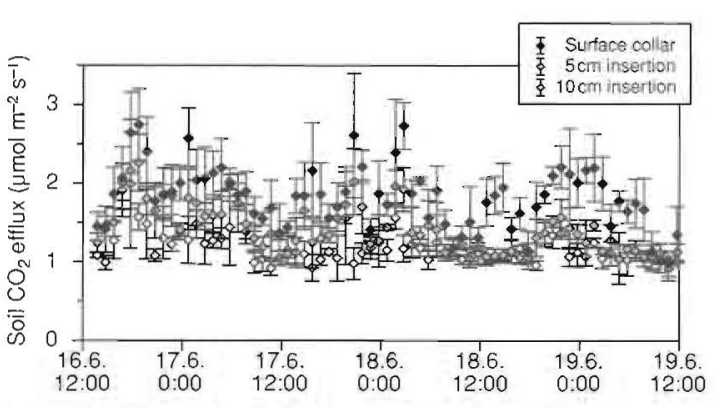

Figure 3.1 Diurnal variation in mean hourly soil $\mathrm{CO}_{2}$ efflux measured in a 15-year-old temperate pine forest (Heinemeyer $t a$ al, unpublishied) using different collar insertion depths of $0 \mathrm{~cm}$ ( surf face collar, black), $5 \mathrm{~cm}$ (gres) and $12 \mathrm{~cm}$ (white). So

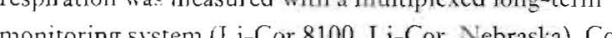
monitoring system (1.i-Cor 8100, Li-Cor, Nebraska). Collar insetion depth is measured from the liter surface and therefore includes the $\mathrm{O}_{1}$, $\mathrm{O}_{\mathrm{f}}$ layer of about $2 \mathrm{~cm}$. Symbols indicate hourly mean fiutes with aror bars or $1 \mathrm{SL}(\mathrm{n}=3$ ) over the period of

et al., 2006, 2007), it might be necessary to monitor additional factors such as plant phenology and root activity for accurate up-scaling procedures. In fact, the role of the autotrophic flux component may have been largely underestimated in the past as soil collar insertion even of only a few centimetres might have cut off a large fraction of the autotrophic carbon supply to fine roots (as shown by Wang et al., 2005) and their associated mycorrhizal hyphae, predominantly living in the top organic rich soil layers. Figure 3.1 shows a reduction in measured surface $\mathrm{CO}_{2}$ flux with increasing soil collar insertion depth in a 15-year-old pine plantation without any ground vegetation. A considerable loss of respired $\mathrm{CO}_{2}$ could be observed for the relatively shallow depth of $5 \mathrm{~cm}$ (which includes $2 \mathrm{~cm}$ of the surface litter layer), and also appears to reduce diurnal variations and overall

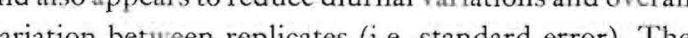
(The

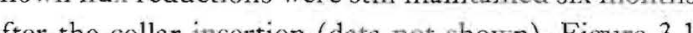
fer ent measured from soil collars, these should be as shallow as possible. It also indicates that the commonly employed 'good practice' of measuring fluxes from collars installed at least 24 hours before measurements is not sufficient to allow natural efflux conditions to re-establish. Good seals with the soil surface can generally be achieved with

Table 3.1 Coefficients of variation (CV) for spatial varnation mithin forested siltes reported for different ecosystems.

\begin{tabular}{|c|c|c|c|}
\hline & $\mathrm{CV}$ & Reference & Comments \\
\hline Boreal forest & $18-45 \%$ & Pumpanen et al. (2003) & $\begin{array}{l}\mathrm{CV} \text { found to increase with magnitude of } \\
\mathrm{CO}_{2} \text { efflux }\end{array}$ \\
\hline Boreal forest & $87 \%$ & Rayment and Jarvis (2000) & \\
\hline Temperate hardwood & $30 \%$ & Davidson et al. (2002) & \\
\hline Temperate coniferous & $28 \%$ & Yim et al. (2003) & Larix plantation \\
\hline Temperate coniferous & $40 \%$ & Buchmann (2000) & $\begin{array}{l}\mathrm{CV} \text { of peak rates in four Picea stands of } \\
\text { different ages }\end{array}$ \\
\hline Temperate coniferous & $42 \%$ & Subke et al. (2003) & $\begin{array}{l}\text { Measured in one of the stands covered by } \\
\text { Buchmann (2000) }\end{array}$ \\
\hline Mediterranean deciduous & $40 \%$ & Tedeschi et al. (2006) & Oak coppice \\
\hline Tropical forest & $30 \%$ & Davidson et al. (2002) & \\
\hline Tropical pasture & $30 \%$ & Davidson et al. (2002) & \\
\hline
\end{tabular}

quite shallow collar insertions. Where this is not possible (e.g. in the absence of a humus layer with relatively brittle mineral soil exposed at the surface), fine roots are likely to be less concentrated in the top soil laycr.

3.2.2 Coping with variability

3.2.2.1 Spatial variability

The previously described sources of biotic and abiThe privers of soll $\mathrm{C}()_{2}$ efllox result in the nata tic drivers of $\mathrm{Soll}_{2} \mathrm{CO}_{2}$ efflur observed spatial sail have experienced recent physical disturbance and have a poorly developed canopy are likely to have significantly more variability than mature stands, while agricultural sites where soils have been homogenized, for example by ploughing, will show a lesser extent of variability. Table 3.1 lists the coefficient of variation $(\mathrm{CV}=$ standard deviation/mean soil $\mathrm{CO}_{2}$ efflux) as a measure of the variability between sampling points in a range of ecosystem types reported in the literature.

Values for the $\mathrm{CV}$ of around $40 \%$ are commonly observed, and the number of sampling locations required to produce a reliable estimate of the actual soil $\mathrm{CO}_{2}$ efluy value is directly dependent on the degree of ariability at a given site. Once the deoree of variability within a stand has been established, the number of samfling points $(n)$ that will produce an estimate within a desired range of the true value for a given probability level is $n=\left[\frac{\tilde{z}_{\mathrm{H}} z^{\sigma} \mathrm{D}}{D}\right]^{2}$, where $z_{\alpha / 2}$ is the critical z-value that is at the vertical boundary for the area of $\alpha / 2$ in the

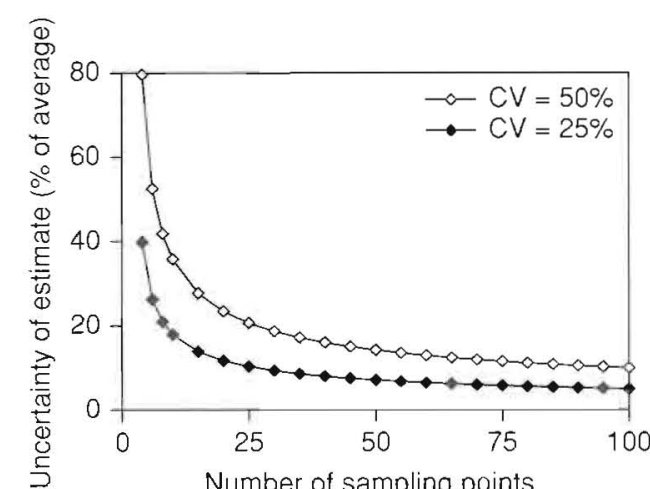

Figure 3.2 Effect of the number of sampling points within stand on the uncertainty of a spatially averaged soil $\mathrm{CO}_{2}$ efflux for a confidence level of 0.05 . The degree of uncertainty shows steep decline as the number of sampling points increases to atrou , and increases directly with the magnitude of the coefficient of

right tail of the standard normal distribution, $\sigma$ is the andard deviation and $D$ is the desired range of the true fflux value (e.g. 20\%). Figure 3.2 illustrates the effect both the number of sampling points and $\mathrm{CV}$ on the egree of uncertainty in a spatially averaged tlux, based n this relationship.

Two studies applying this analysis to extensive atasets (mixed temperate hardwood forest by David(20) et al. (2002), and Larix plantation by Yim et al. (2003)) showed that for a CV of $c .30 \%, 8$ to 10 sampling points are required to reach $20 \%$ of the rrue site $\mathrm{CO}_{2}$ 


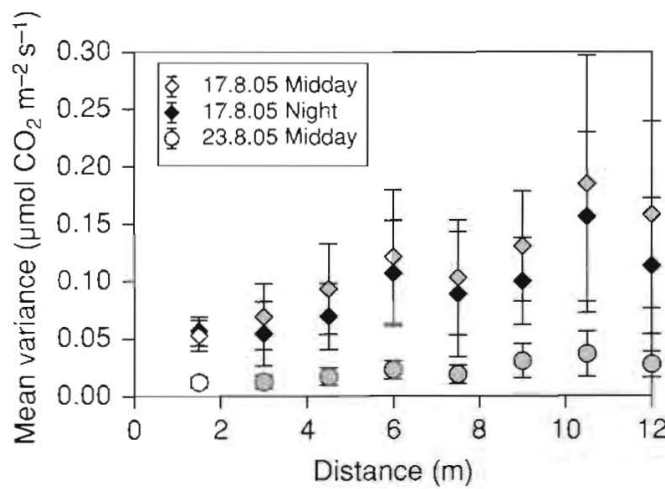

Figure 3.3 Effect of sampling distance on mean soil $\mathrm{CO}_{2}$ efflux $\left(\mu \mathrm{mol} \mathrm{m}^{-2} \mathrm{~s}^{-1}\right)$ at a UK heather moorland site (Heinemeycr et al., unpublished). Mean variances are based on soil respiration measured from eight locations with $1.5 \mathrm{~m}$ spacing using a $\mathrm{Li}-\mathrm{Co}$ 8100 system (measured on $20 \mathrm{~m}$ deep $\mathrm{m}$ C collars, error bars indicate ser 2005: (wet after wateroging on the 23 August.

efflux at a 95\% confidence level, while 30 to 40 sampling points are required for estimates to be within $10 \%$ of the site mean at the same level of confidence. Another commonly overlooked issue is the spatial autocorrelation, i.e. the closer the flux sampling points to each other, the more similar are the expected soil $\mathrm{CO}_{2}$ effluxes. This behaviour can be analyzed by geostatistical variogram. analysis (Cressie, 1993) and should be accounted for in the sompling desis by placing sompling points for in the sampling design by placing sampling points for enough from each oher to guarantee statistical independence and to avoid pseudo-replication (Hurlbert, 1984). Figure 3.3 illustrates the degree of spatial heterogeneity at a moorland flux site in England (Ma ham Tarn) where soil $\mathrm{CO}_{2}$ efflux has been measured along a transect with regular collar spacing of $1.5 \mathrm{~m}$. The mean variance for a given collar distance (i.e. multiples of $1.5 \mathrm{~m}$ in this case) can be calculated according to: $\gamma(d)=\frac{1}{2 n} \sum\left(R_{x}-R_{y}\right)^{2}$, where $\gamma$ is the mean variance (i.e. a measure of the similarity) between collars, $d$ is the distance between collars, $n$ is the number of pairs of observations in any of the distance classes and $R$ is the soil $\mathrm{CO}_{2}$ efflux measured on any two collars ( $x$ and $y$ ).
3.2.2.2 Temporal variability

Owing to the natural fluctuations in biotic and abiotic drivers of soil $\mathrm{CO}_{2}$ efflux, observed rates commonly show a pronounced seasonal and diurnal varibity Studies aiming to quntify soil $\mathrm{CO}_{2}$ fflux orer lity. periods have to ensure that all key efflux situe to summer drought, rewetting, budburst etc.) are well represented by the sampling strategy. Thus the sampling frequency needs to allow a meaningful interpolation of measurements in order to adequately describe the total integrated soil $\mathrm{CO}_{2}$ efflux. However, as with capturing the spatial variability, this requirement is most commonly limited by the cost of materials or labour involved. Additional bias may be introduced if soil $\mathrm{CO}_{2}$ efflux is always sampled at the same time of day, miss-

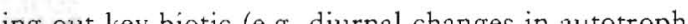
riges in autotrophic activity) and abiotic (e.g. ith depth) components.

Soil $\mathrm{CO}_{2}$ efflux is strongly correlated over time and while there is usually a pronounced diurnal variability in surface fluxes, these tend to show relatively small changes between successive days. Fluxes measured from the same location after only a short time interval are therefore not independent observations and may confound the statistical analysis in an experiment. Semivariance analysis is a useful tool to analyze the degree of autocorrelation orer time and helps to determine the adequa sumpling interval in order to aved mine the adecute sampling interval in order to avoid oversampling. Figure 3.4 illustrates the degree of correlation between soil surface $\mathrm{CO}_{2}$ fluxcs with an increasing time lag. The graph shows local minima between fluxes at the same time of day (i.e. time lag of multiples of 1 day), with a general increase in variance over the first 5 days. Thereafter, variances between efflux measurements are relatively constant while still retaining the lowest variance for measurements made at the same time of day For this particular site, it can therefore he concluded that a periodic sampling strategy with

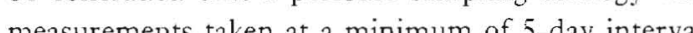
measurements talen at a minimum of 5 -day interval prevent autocorrelate

To further assess both the impact of sampling interval and potential biases resulting from selective sampling at specific times of the day, soil $\mathrm{CO}_{2}$ efflu from the same dataset of continuous hourly soil $\mathrm{CO}_{2}$ efflux data was 're-sampled'. To simulate periodic sampling, fluxes were averaged either for the morning hours

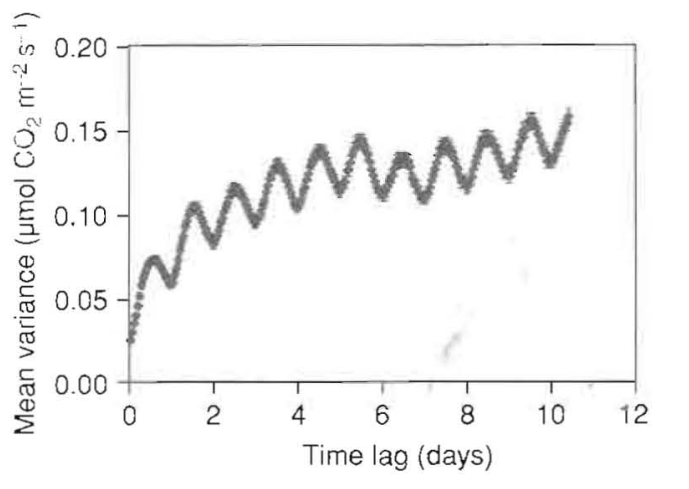

Figure 3.4 Mean variance of hourly soil $\mathrm{CO}_{2}$ efflux values with fluxes measured from the same locations, but with increasing time lags. Variances were computed for a dataset with hourly flux measurements (disregarding data gaps) over three periods of the growing season (29 April 1999 + July 1999, 28 July 1999-7 September 1999 and 29 October 1999-2 December 1999) in a mature temperate spruce forest (see Subke et al., 2003). The complete dataset includes 3476 hourly flux measurements, allowing variances to be calculated for between 3344 (interval = hour) and 2324 (interval $=10$ days) pairs of flux values. Error bars indicate standard errors for the calculated variances.

(9 a.m.-1 p.m.), or for daytime measurements ( 9 a.m. -6 p.m.), for 1 day, 2 days, bi-weekly, weekly or fortnightly sampling intervals. The analysis shows that increasing the sampling interval results in increasing deviations from the continuously measured average (which for the purpose of this analysis is assumed to represent the true site efflux), reaching values of up to $10 \%$ (Fig. 3.5). The error bars in Fig. 3.5 indicate the lower degree of certainty of low frequency measurements owing to the smaller number of sampling dates. Parkin and Kaspar (2004) rcport a similar increase in cumulative $\mathrm{CO}_{2}$ flux estimate with increasing lengths of sampling intervals.

Figure 3.5 further shows a small but consistent bias resulting from the different periods within a day over which samples were collected. At this particular site, soil $\mathrm{CO}_{2}$ efflux showed a slow increase after sunrise, following the temperature increase in the soil. Peak values $x$ ere commonly observed in the early afternoon and fluxes declined slowly before dropping after sunset. In this example, fluxcs mcasured bctween 9 a.m. and 1 p.m. were a better rupresentation of the actual site mean efflux than those collected between 9 a.m.

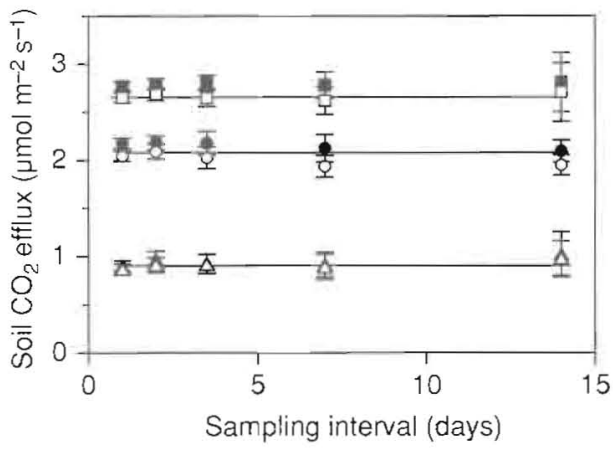

Figure 3.5 Effect of re-sampling a continuous dataset of soil $\mathrm{CO}_{2}$ efflux measured in a mature temperate spruce forest (see Subke dicare mear fures with orror bars of ISE, while horions lines indices the mean fux obtuined from the continuons dataset. Circles: 29 April 1999-4 July 1999; squares: 28 July 1999-7 September 1999. triangles: 29 October 1999-2 Devemb 1999. For each period, open symbols are averame fluxes messured between $9 \mathrm{am}$ and $1 \mathrm{pm}$, while solid symbols are fluycs measured berween 9 a.m. and 6 p.m.

and 6 p.m. Pair-wise comparison of fluxes in the first sampling period of Fig. 3.5 showed a significant difference between fluxes obtained during the morning and those obtained throughout the davtime hours $(t=$ $7.21, p<0.001$, while neither of the estimates differed significanty from the true 24 -hour men of correspond-

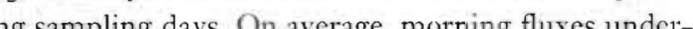

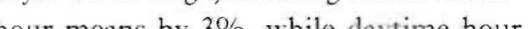
este e same nut $\mathrm{Notab}$ the time bes in the . Notably the time lags in the diurn soil $\mathrm{CO}_{2}$ efflux dynamics differ according to site conditions and the relatively small error introduced by either morning or daytime sampling in this example cannot be automatically assumed to hold for different sites. Data in Fig. 3.1, for example, show peak values at around midnight which is likely to be due to the time lag for ssimilation products fixed throughout the day to reach the rots and rhizosphere.

Correcting any possible bias resulting from the time of day during which sampling took place may be posible if the diurnal variation of soil $\mathrm{CO}_{2}$ efflux (meaning day- and night-time fluxes) is measured repeatedly hroughout the measuring period. If the bias is constant throughout the period, a simple multiplicative correction may suffice; alternatively, a simple soil temperature model may be necessary to correct fluxes. 
Table 3.2 Comparison of attributes for automated and manually operated soil $\mathrm{CO}_{2}$ efflux measuring systems. Please nole that there is a considerable variety of measuring principles, so that mithin each of the tmo categories indiridual aspects may vary.

\begin{tabular}{lll}
\hline \hline & Automated system & Manual system \\
\hline Measuring frequency & continuous & periodic \\
Number of sampling points & small & high \\
Technical requirements & high & low \\
Labour intensity & low & high \\
Capture of spatial heterogeneity & low & high \\
Capture of temporal heterogeneity & high & low \\
\hline Suited for & Time series analysis & Areal survey \\
& Capture of 'events' & \\
\hline \hline
\end{tabular}

3.2.2.3 Implications for soil $\mathrm{CO}_{2}$ efflux sampling trategies

Soil $\mathrm{CO}_{2}$ efflux measurements using chambers in the field are commonly done by either continuous automated systems or manually operated chambers with measurements carried out in periodic campaigns (see Chapter 2 Pumpanen $e t$ al. for a more detailed descripCho f measuring methods) The choice of a measuring Con of system Te 3.2 provides a seral overvew of ment. Table 3.2 provides a general overview of the attributes of automated continuously measuring systems and those of manually operated systems. However, while these attributes are generally correct, there is considerable variability within each category. A further constraint is commonly posed by the availability of rcsources to invest in either materials or labour, which are assumed to be restrictive for this comparison. Given a big enough budget, it is feasible to either measure with a continuous system from a high number of samplin points or to measure fluxes manually at high frequency, hus compensating for some of the aspects highlighted in Table 3.2.

In their investigation into trade-offs between the resolutions of either measuring mode, Savage and Davidson (2003) conclude that the manual mode is beneficial for investigations where the mean soil $\mathrm{CO}_{2}$ efflux of a site is under investigation, with significant reductions in the $95 \%$ confidence intervals owing to the better capture of spatial heterogeneity. However, this sampling mode was not well suited for capturing short-term changes in soil $\mathrm{CO}_{2}$ efflux, for example following wetting events or changes in temperature Studies interested in empirical modelling of soil $\mathrm{CO}_{2}$ efflux to environmental factors would therefore benefi from data obtained from automated continuous measurements. A combination of both approaches is advisable in order to avoid bias due to the shortcomings of ither temporal or spatial representation.

Experimenters operating continuous systems with low spatial replication are well advised to first assess spatial heterogeneity with a survey chamber in order to test how representative the continuous sampling locations are. Again, this survey should ideally be repeated throughout the annual cycle if measurements are to be used for extrapolation of annual fluxes.

\subsubsection{Laboratory measurements}

Laboratory incubations of soils allow a close investigation of the respiratory response to specific environmental parameters (most commonly temperature and soil moisture), or soil amendments with respiration substrates, nutrient solutions or pollutants (Dilly and Nannipieri, 2001; Allen and Schlesinger, 2004; Miller et al. 2005; Smith, 2005; Shaver et al., 2006). The obvious advantage is the level of control over a range of parameters (both biotic and abiotic) influencing soil $\mathrm{CO}_{2}$ efflux under field conditions, allowing a clearer interpretation of results from experimental treatments. Depending on the experimental aims, soil samples from the field may be left intact as complete monoliths or separated into different soil components (surface litter, organic horizon(s), mineral soil and roots). Soil extraction from the eld and incubation in the laboratory by its very nature teld and ince ba to

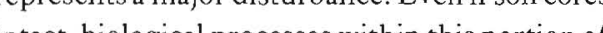
intact, biological processes with this porion significantly affected by the physical disturbance during extraction and interruption of the autotrophic connec tions (i.e. roots and mycorrhizal hyphae). Depending on the mode of soil sampling, local compaction or loosening of the soil matrix is possible, with considerable influence on soil diffusivity due to artificial changes in soil pore space volumes. Roots that were severed are likely to lose labile organic compounds ('wound respiration') in the short term (Cabrera and Saltveit, 2003), wile the obvious lack of carbon in ant from the plnts la in subsequen loss of exudations from roots within the soil core means that substrate supply to a host of microbial organisms have been removed. The result is a rapid decline in soil $\mathrm{CO}_{2}$ efflux in the initial period (on the time scale of hours to a few days) following soil extraction in the field (Reichstein et al., 2005). Ultimately, roots (and any other directly dependent organisms such as the mycorrhizal mycelium) within the core will die, so that the amount of dead biomass is artificially increased with respect to soil conditions at the site the sample was taken from.

Laboratory incubations of root-free soil, on the other hand, can be used to estimate the carbon mineralzation potential of different soil parts or the microbial heterotrophic response to temperature and soil moisture conditions. Due, again, to the inherent disturbance by the sampling process and subsequent separation of soil components, there is a clear limitation to the possibility of extrapolating soil $\mathrm{CO}_{2}$ efflux obtained in laboratory incubations to field conditions. For investigations aiming at quatify the soil $\mathrm{CO}_{2}$ effur under feld condivions or addressing any hypothes involver in on intact autotrophic flux component, measurements made on laboratory incubated soil samples alone are not suitable as an experimental approach. However, soil $\mathrm{CO}_{2}$ efflux studies based on laboratory incubations have been instrumental in supplementing field-based measurements by separating out individual aspects of soil $\mathrm{CO}_{2}$ efflux responses to environmental conditions (Fang et al., 2005; Miller et al., 2005; Reichstein el al., 2005) the potential of $\mathrm{CO}_{2}$ being mineralized from different forest sites (Person, 2000; Sjoberg et al., 2004), well as investigations of the stability of soil organic atter fractions (Franzluebbers et al., 2001; LadegaardPedersen et al, 2005; Leifeld and Fuhrer, 2005) or effects of pollution and soil amendments on soil microbiota (Rajapaksha etal., 2004; Fuentes et al., 2006; Oorts al., 2006).

\subsubsection{Scaling up}

caling up in space and time is always based on the genealization of the data with respect to factors controlling the variation. Day-to-day and seasonal variation in time is often largely dependent on temperature, soil moisture and simple measures of vegetation activity (such as leaf andex) and can be modelled relatively easily. The a la pling (e. cabon pool dyna dis-

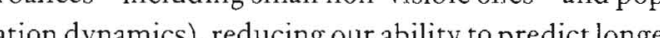
(eyches erm cycles and trends in soil efflux. Similarly, spatia variation can be modelled quite well along gradients where temperature, soil moisture regimes and vegetaton productivity are the dominating factors (e.g. along continental gradients) (Reichstein et al., 2003). As soo as those factors are less dominant, subtler but important factors might come into play: prominently soil chemcal status (e.8. pH, nutrients), regetation cover and

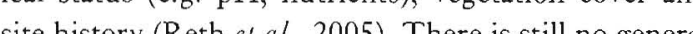

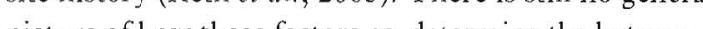
site variation of soil respiration. Consequ

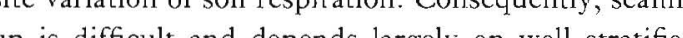
up is difficult and depends largely on well stratified sample databases. Typical models addressing temporal and spatial variation at different scales are discussed in Chapters 11 and 12

3.2.5 Site variation: random, stratified or systematic design, and avoiding bias

part from sampling soil $\mathrm{CO}_{2}$ efflux from a sufficient number of locations according to a site's heterogeneity, the allocation of adequately spaced sampling poin (see Section 3.2.1 for autocorrelation issues) is equally important in order to achieve a representative estimat of the true soil $\mathrm{CO}_{2}$ efflux value. An appropriate design will vary according to the site conditions and depend on the question to be answered. Mainly there are three types of sample design: (1) random, (2) stratifed or (3) systematic Whereas (1) assume faily uniform sie 


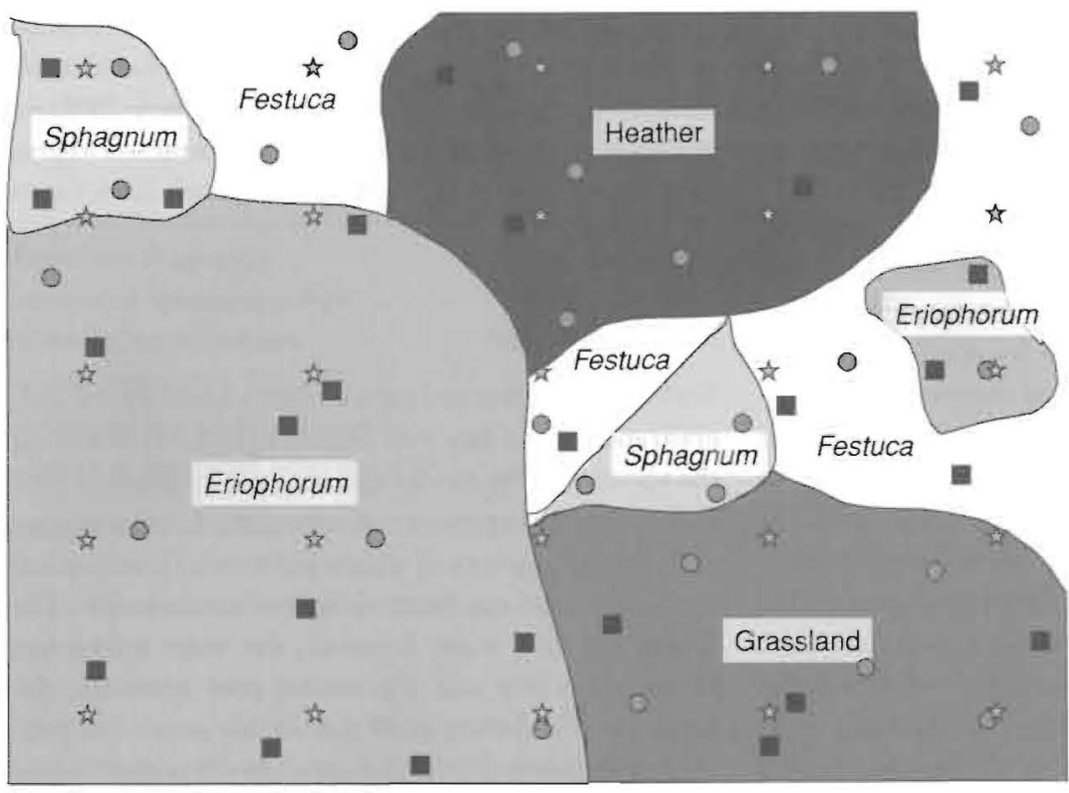

Figure 3.6 Example of three different sample designs for assessing $\mathrm{CO}_{2}$ efflux site variahility in a heather moorland with a patchwork, h: squares and circles represent the

random and stratified design, respectively, wherens a sistematic approach would cover the area in 25 equally spaced points (stars).

conditions (e.g. old beech forest on brown earth), (2) is more suitable for sites with known spatial vaibit ii: (e.g. heathland covering a patchwork of soil types with diffcrences in dominant vegetation types and slope variation). Systematic sampling (3) might be considered as straightforward but ignores underlying site variabilty. However, it is suitable to answer questions such as variance distance relationships ( $\operatorname{scc}$ Section 3.2.1 for semivariogram-based analysis). More information on sampling approaches is given in fiurlbert (1984).

From Fig. 3.6 it is clear that using different sample stratcries will lead to different results In a first approach cill only consider one environ mel factor, we will only consore 'ence estimatc. In our case (1ig. 3.6), the random design will not only misrepresent the patchwork of dominant vegeation types, it will also lead to a bias towards Eriophorum coverage (11 sample points vs. only 3 for Sphagnum). Both would be much better accounted for by a stratified design (5 sample points for each vegetation zone). To make sure there is no further bias introduced the stratified design needs to be allocated in a randomized way, i.e. sample points should be given coordinates based one (c.g. five random coordinates for each vegetation tocus on assessing the 'dominant site soil flux' allocatin measurements to the dominant vegetation type, hus the stratification must be weighted according to the proportion of the total area occupied by each vegetation

A different approach altogether would be to include many more environmental variables, which would cmand more sophisticated geostatistical methodolog such as sampling of assembled data, for which examples are given in McBratney et al. (2003). For example, constrined Nonte Catb sampling schere sclects Cacto

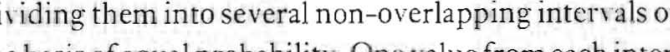
作 al is sclected at random with respect to the probability density in the interval. The obtained $\mu$ values are the paired in a random manner between the many environmental variables until $\mu$-duplets are formed; searchin through the data can then find the locations that are waxonomically most similar to the combination of values chosen (e.g. heather on deep peat), or find location that match the intervals in the various variables (e.g.
$\mathrm{pH}$ ranges). In either case, this will result in a set of both might strongly impact on the measured soil $\mathrm{CO}_{2}$ $\mu$ spatial coordinates (locations) for observation (see McBratney et al, 2003). There are many other sophisticated geostatistical procedures and practicalconsiderions, and the reader may want to consult MeBrathey al. (2003) for useful examples on related geostatistial methods such a $\mathrm{K}$ iging which a process by which values are estimated at those loc tions that have not been sampled. The technique uses weighted average of neighbouring samples to estimate the 'unknown' value at a given location, which can be optimized using the semivariogram model. The technique also provides a 'standard error', which may be used to quantify confidence levels. Co-Kriging uses similar interpoltion technique but estimates map valy if the distibution of a secondary variab casily be variable.

2.6 Using geographical information systems (mapping and querying)

An alternative to the complex geostatistical procedures mentioned above is the use of a geographical information system (GIS), which can help considerably with the

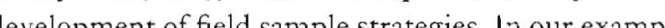
. the stratifed of might change considerably if sample point allocation is weighted on a vegetation type area basis as done by Garnett et al. (2001) for soil sampling. This weighted allocation will reflect the soil fluxes under different vegetation covers in proportion to their area, thus providing an undistorted mean flux estimate for the entire site. There are many GIS software packages available offering different levels of complexity and user knowledge, and the reader may wish to consult specific literature. In many cases a wide varety of plot or lache

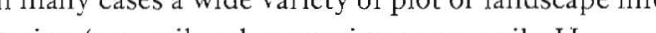
mation (e.g. soil and vegetation types, $5.1 \mathrm{pH}$, organic a given area on which sample strategy can be based. given area on which sample strategy can be based. However, it will become increasingly difficult to display and query those data in conventional software in order to assist with sample design. In a GIS such digitized data are then imported as either polygons (areas) or point information that can then be used to draw map layers and to query any combination of layers. For exampe, the soil type in Fir. 3.6 might actually not overla with the domint vegetaion or there might be step lopes across the heather and grassland comm

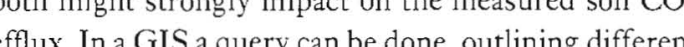
zones based on all query can be done, qilable (eg including sope grades), on which a more accuract the intention would be to sample the reference area as outlined above in order to fit model and extrapolate to the rest of the area. This might give a better chance of fitting local relationships with given sampling effort, and should be more efficient in equired field time

The GIS approach may also help with the spatial display of soil fluxes and to model point measuremen integration (e.g. plot interpolation, see Kaye and Hart, 1998), which an be done using quite a diverse set of procedures (e surfoce or orid interpo if iflarger than plot scale information is avaliable, such as land use, vegetation or soil maps, then scaling up the integrated plot results to the landscape is achievable in a GIS using spatial information, as done by McBratney et al. (2000) for soil mapping.

\subsection{FORMLLATING AND TESTING}

\section{HYPOTHESES}

Whereas the previous part of this chapter provides critical knowledge for observation-based science (e.g. obtaining meaningful spatial and temporal site flux variations) the following also considers theoretical and practical issues related to experimental manipulation (e.g. hypothesis testing). The basis of science is the formulation and testing of hypotheses by applying experimental treatments, which distinguishes it from purely assessing temporal and spatial flux variability as outlined previously. It is assumed that the null hypothesis is true and the scientist will look for evidence in the con A fun the null hypothes is true unil there is ove whelming evidece aginst it (typicaly, less do a 196 or $5 \%$ chence of obst in (eypically, less than a $1 \%$ or $5 \%$ chance of obtaining the observed value or one more extreme if, in fact, the null hypothesis were

However, it is not always easy to formulate clea and testable hypotheses or design a balanced experimen with appropriate controls. Therefore, care should be taken to follow certain guidelines, which will lend to successful experimental testing of hypotheses and thus observational disciplines such as natural history or eve 
provide meaningful answers. In the following section we suggest an experimental step-bv-step approach as a basis for scientific hypotheses testing, which can be summarized in five steps.

1. Make the observation.

2. Fornulatc the hypothesis.

3. Draw the graph

4. Design and perform the experiment

5. Evaluate data with the appropriate statistical design

Although the following section will be sufficient in a soil respiration context, there might be additional precautions needed to ensure successful hypothesis testing under special circumstances (c.g. when measuring in unusual environments). The most common mistakes are made by having (1) an inappropriate or $\mathrm{n}$ control treatment at all or (2) no pre-treatment data; this fivc-step approach is intended to prevent such mistake.

3.3.1 Make the observation

Soil respiration data are used to inform models about site-specific soil $\mathrm{CO}_{2}$ efflux behaviour throughout the year in order to improve model performance (see Chapter 11 Reichstein and Janssens). As explained above, the annual cycle might be divided into sereral key soil respiration process stages (e.g. snow cover, thawing, bu burst etc.). Thus different observations throughout the year might lead to addressing different hypotheses. For example, the observation might be that winters with les snow cover result in comparatively low soil respiratio flux as observed by Monson et al (2006). One might link this to better soil insula this to beter soll indlation to warmer soll tempcratures and thus higher microbial activity, or protecting roots from frost damage. How ever, the observation needs to be tested scientifically, it is not enough to compare one year with another as other factors leading to higher soil respiration fluxes might have changed as well, which crucially remaine unobserved.

\subsubsection{Formulate the hypothesis}

The hypothesis based on the above observation can be phrased as: 'Soil $\mathrm{CO}_{2}$ efflux increases with depth of snow cover'. The null hypothesis that is going to be tested statistically therefore states: 'Higher snow cover tested statistically therefore states: 'Higher snow'
depth does not result in higher soil $\mathrm{CO}_{2}$ efflux'.

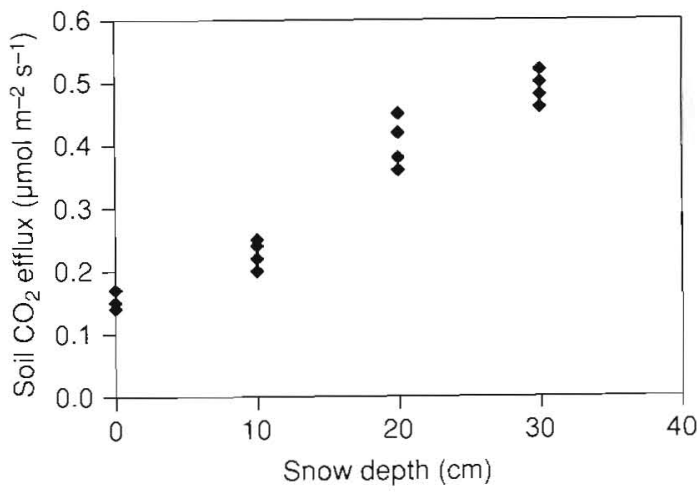

Figure 3.7 Hypothetical graph illustrating the expected correlation between soil respiration ( $y$ axis) measured under snow depths treatments $(x-$-axis) on which the hypothesis is base $(n=4)$. Note that the correlation is expected to be non-linear; consequently flux measurements at more than two snow depths treatments are needed. Furthcr, the dependent variable is place on the $y$-axis, indicating that soil respiration depends on snow depth and not the other way round.

3.3.3 Draw the graph

A first graph (Fig. 3.7) aims at illustrating the hypothesis - in this case a correlation. It is important to note that drawing the graph at this stage does not reflect a foregone conclusion of the outcome of the experiment. The graph reflects one possible outcome (base on the observations that led to the hypothesis), it is intended as a guide towards the most adequate statistical test.

In this graph we already include a critical aspec for the sampling strategy: as we do not know whether there is a critical snow depth from which the hypothcired insulating effect becomes offective (i.e. a likely non liner rel to respiration rates), wo will impose four different sno depth treatments. Howerer, as it is possible that there is a minimum time to produce a reduction in flux activity by frost penetration into the soil, we will have to extend the previous plan (Fig. 3.7) and add repeated flux measurements. Based on this, we may proceed wit a second hypothetical graph, which sets out the logistics of the experiments; showing extended fortnightly sampling over 15 weeks (Fig. 3.8). Please note that this example is intended to give a guide to the planning of an

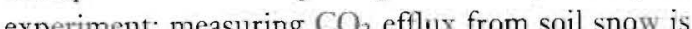
constion et al., 2006) and is not part of this exercise. Given that we

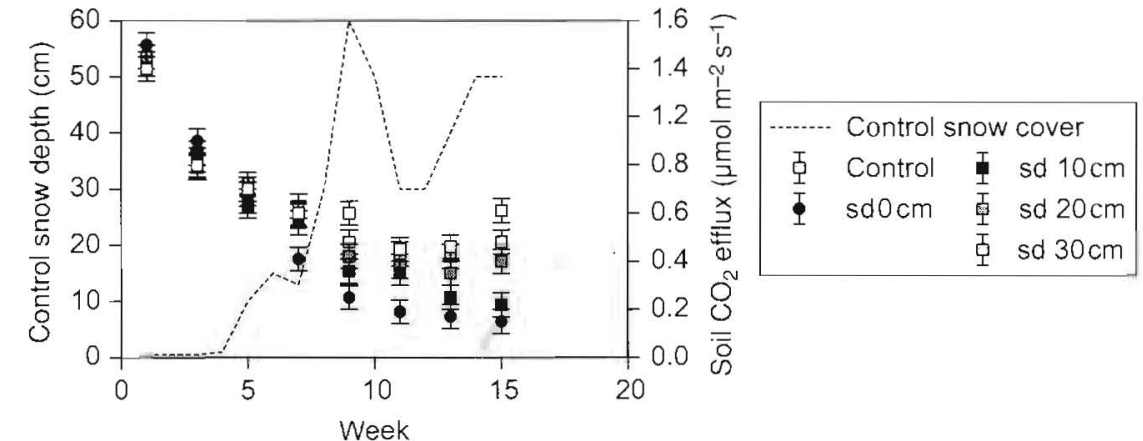

Figure 3.8 A hypothetical graph for the experimental testing of the hypothesis that snow depth is positively related to soil $\mathrm{CO}_{2}$ efflux Symbols indicate predicted fortnightly soil respiration fluxes ( $\pm 1 \mathrm{SE}$ is an indication that we need more than three replicates!) on the right $y$-axis for the four snow depth (sd) treatments (i.e. snow depth limited to a maximum depth of either $0,10,20$ or $30 \mathrm{~cm}$ b A hepotherical natural snow cover deptl for the unswept control (natural snow cover) is indicated on the left $y$-axis (broken line) Note that the final data (week 15) correspond to the hypothetical data presented in Fir. 3.T.

want to repeat measurements from the same locations, and compare the fluxes from different snow depths, the appropriate statistical test is an analysis of variance (ANOVA) with repeated measures. This also ba implications for the sampling strategy as the number of replicates required for each treatment has to be sufficient to yield the statistical power to resolve possible differences. Further, the practical guidance for semivariogram asessmet for pratiand temporaf surements in order to avoid pseudo-replication should by considered (see Section 322 1)

By drawing this second graph (Fig. 3.8), an including hyporhetical error bars, we are automatical guided to the material requirements of the measuring process and we can instantly recognize if this will, for example, conflict with the capabilities of the measurin system (number of collars available, time required to complete measurements from all locations etc.) or time issues (e. holidays). Also note the pre-snow messurements ind hed in Fig 3.8, which are ciral to reve

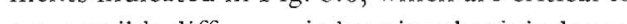
Deentils the snow depths. Details such as pre-treatment fluxes,
controls and time issues are easily overlooked, and the controls and time issues are easily overlook
graph is intended to avoid such mistakes.

\subsubsection{Design and perform the experiment}

Based on this example, we would plan to measure soil $\mathrm{CO}_{2}$ efflux from 15 locations beginning well before the first snowfall at fortnightly intervals. These 15 collar are divided into five different experimental groups (four imposed snow depths and one 'control' of natural snow height), using a rando anized bock design (see Hurlbert, 1984) to ensure thato the block design (see Hurlber, tical. In the blocked treatment design, the selected measurement locations are spatially allocated within a block containing a full set of treatments, and blocks are space widely enough to avoid pseudo-replication. Blocking can also be used to create a more homogeneous experimental test bed according to similarity criteria, which are idcally based on a pre-treatment ranking (e.o. three blocks with each containing the three plots with highest, medium and lowest soil $\mathrm{CO}_{2}$ efflux rates). Experimental blocking has two major advantages, both of which increase the statistical power as the block effect can be 'deducted' from the data: (1) it will reduce within-block variability and (2) it can take into account potentia environmental gradients (e.g. of soil moisture or $\mathrm{pH}$ ). As snow depth increases with time, regular sweeping achicres the imposd snow depth of ach sweeping efflux at fortnightly intervals.

3.3.5 Evaluate the data with the appropriat statistical design

For the statistical analysis, all flux data collected from the time when the snow cover cxceeds $30 \mathrm{~cm}$ (i.e. after weet 8 in Fis 3.8, in this example) would be considered. Other tests may be considered to look, for example, at 
the variation of temperature (in air) and below the different snow depth treatments (in the soil) during the experiment. These factors may be included in the statistics by means of an analysis of covariance (ANCOVA). For more detailed advice on choosing appropriate statistical tests the reader may wish to consider special literature such as Dytham (2003).

\subsection{CONCLUSION}

Capturing the spatial and temporal heterogeneity of soil $\mathrm{CO}_{2}$ cfflux is one of the biggest challenges to obtaining flux estimates that allow scaling up to larger scales. The aim of this chaptcr was to introduce the reader to the sources of variability, and to illustrate possible theoretical and practical approaches in order to allow meaningful measurements of complete flux sums. As we have pointed out throughout this chapter, variability of fluxes in time and space is strongly influenced by sitespecific conditions and the methodology used. For the purpose of scaling up, it would be desirable to separate individual influences on soil $\mathrm{CO}_{2}$ efflux, since simplistic prameterizations hold the risk of $\mathrm{Con}$ founding different parames of fare efflux through the growing late reasonably well with temperature (and possibly soil moisture), a simple parameterization on these factors alone will likely mask their indirect influence on plant activity, which in turn affects soil $\mathrm{CO}_{2}$ efflux. A good spatial coverage including the experimental separation of autotrophic and heterotrophic fluxes in the field, and independent parameterization is likely to provide a more meaningful basis for larger scale modelling, where plant activity can be modeled independently, and thus proiding a possible input parameter for autotrophic floviding a poss hl input pare for a flux contributions. Hower needs to be based on a sound statistical design and
we hope that our experimental step-by-step approach we hope that our experimental step-by-step approach will be useful to the field scientist responsible for obtaining 'meaningful numbers' on soil carbon turnover processes.

\section{REFERENCES}

Allen, A. S. and Schlesinger, W. H. (2004) Nutrient limitations to soil microbial biomass and activity in

loblolly pine forests. Soil Biology and Biochemistry, 36 581-9.
Atkin, O. K., Edwards, E. J. and Loveys, B. R. (2000) Response of root respiration to changes in temperature and its relevance to global warming. Nem Phytologish, $147,141-54$

olin, B. (2000) Global perspective. In I.surd Use, Land Use Change, and Forsetion. A Special Report of the Intergiverniticitat Pontel on Climate Change (IPCC), ed. R. T. Watson, I. R. Noble, B. Bolin, N. H. Ravindranath, D. J. Verardo and D. J. Dokken. Cambridge: Cambridge University Press, pp. 23-51.

Buchmann, N. (2000) Biotic and abiotic factors controlling soil respiration rates in Picea abics stands. Soil Biology and Biochemistry, 32, 1625-35.

Cabrera, R. M. and Saltreit, M. E. (2003) Survey of wound-induced ethylene production by excised root segments. Physiologia Plantarum, 119, 203-1

ressie, N. A. C. (1993) Statistics for Spatial Data. Wiley Series in Probability and Mathematical Statistics, Rev edn. New York: Wiley.

Davidson, E. A., Savage, K., Verchot, L. V. and Navarro, R. (2002) Minimizing artifacts and biases in chamber-based measurements of soil respiration. Agricultural and Forest Meteorolog, 113, 21-37. A Bor, E. W. 作 production within a temperate forest soil. Global Chang Biology, 12, 944-56.

Dilly, O. and Nannipieri, P. (2001) Response of ATP content, respiration rate and enzyme activities in an arable and a forest soil to nutrient additions. Biology and Fertility of Soils, 34, 64-72.

Dytham, C. (2003) Choosing and Using Statistics: A Biologist's Guide. Oxford: Blackwell Scicnee.

Fang, C. and Moncrieff, J. B. (1998) Simple and fast technique to measure $\mathrm{CO}_{2}$ profiles in soil. Soil Biologgy and Biochemistro, 30, 2107-12.

Fing, C., Smith, P., Moncrieff, J. B. and Smith, J. U. (2005) Similar response of labile and resistant soil organic matter pools to changes in temperature. Nature, 433 $57-9$

Franzluebbers, A. J., Haney, R. L., Honeycutt, C. W. et al. (2001) Climatic influences on active fractions of sol organic matter. Soil Biology and Biochemistry, 33, $1103-11$

Fuentes, J. P., Bezdicek, D. F., Flury, M., Albrecht, S. and Smith, J. L. (2006) Microbinl activity affected by lime in lithe $123-31$
Garnett, M. H., Ineson, P., Stevenson, A. C. and Howard, D. C. (2001) Terrestrial organic carbon storage in a British moorland. Global Change Biology, 7, 375-88.

Heinemeyer, A., Ineson, P., Ostle, N. and Fitter, A. H. (2006) Respiration of the external mycelium in the arbuscular mycorrhizal symbiosis shows strong dependence on recent photosynthates and acclimation to temperature. New Phytologist, 171, 159-70.

Heinemeyer, A., Hartley, I. P., Evans, S. P., De la Fuente, J. A. C. and Ineson, P. (2007) Forest soil $\mathrm{CO}_{2}$ flux: uncovering the contribution and environmental responses of ectomycorrhizas. Global Change Biology, $13,1786-97$.

Hirano, T. (2005) Seasonal and diurnal variations in topsoil and subsoil respiration under snowpack in a tempcrate deciduous forest - art. no. GB2011. Giob Biogerechemical Cycles, 19, B201

Högherg, P., Buchmann, N. and Read, D. J. (2006) Comments on Yakov Kuzyakov's review 'Sources of $\mathrm{CO}_{2}$ efflux from soil and review of partitioning methods' (Soil Biology' and Biochemistry, 38, 425-48). Soil Biology and Biochemistry, 38, 2997-8.

Hurlbert, S. H. (1984) Pseudoreplication and the design of ccological field experiments. Ecological Monographs, 54 $187-211$

Janssens, I. A., Kowalski, A. S., Longdoz, B. and Ceuleman R. (2000) Assessing forest soil $\mathrm{CO}_{2}$ efflux: an in situ comparison of four techniques. Tree Physiology, 20 23-32.

Jenny, Il. (1980) The soil resource: origin and behaviour. New York: Springer-Verlag.

Kaye, J. P. and Hart, S. C. (1998) Restoration and canopy-type effects on soil respiration in a ponderosa pine-bunchgrass ecosystem. Soil Science Saciety of America fournal, 62, 1062-72.

Kuzyakov, Y. (2006a) Sources of $\mathrm{CO}_{2}$ efflux from soil and review of partitioning methods. Soil Biology and Biochemistry, 38, $425-48$.

Kuzyakov, Y. (2006b) Response to the comments by Peter Högberg, Nina Buchmann and David J. Read on the review 'Sources of $\mathrm{CO}_{2}$ efflux from soil and review of partitioning methods' (Soil Biology and Biochemistry', 38, 425-48). Soil Biology and Biochemisty, 38 2999-3000.

Ladegaard-Pedersen, P., Elberling, B. and Vesterdal, L. (2005) Soil carbon stocks, mineralization rates, and $\mathrm{CO}_{2}$ effluxes under 10 tree species on contrasting soil types. Canadian Fournal of Forest Research, 35, 1277-84
Law, B. E., Baldocchi, D. D. and Anthoni, P. M. (1999) Below-canopy and soil $\mathrm{CO}_{2}$ fluxes in a ponderosa pine forest. Agricultural and Forest Metcorology, 94, 171-88.

L.eifeld, J. and Fuhrer, J. (2005) The temperature response of $\mathrm{CO}_{2}$ production from bulk soils and soil fractions is related to soil organic matter quality. Biogeochemistry, $75,433-53$

Liang, N. S., Nakadai, T., Hirano, T. et al. (2004) In situ comparison of four approaches to estimating soil $\mathrm{CO}_{2}$ efflux in a northern larch (Larix kaempferi Sarg.) forest. efflux in a northern larch (Larix kaempfert Sarg.)
Ayricultural and Forest Meteorology, 123, 97-117.

McBratney, A. B., Odeh, I. O. A., Bishop, T. F. A., Dunbar, M. S. and Shatar, T. M. (2000) An overview of pedometric techniques for use in soil survey. Geoderma, 97, 293-327.

McBratney, A. B., Santos, M. L. M. and Minasny, B. (2003) On digital soil mapping. Geoderma, 117, 3-52.

Miller, A. E., Schimel, J. P., Meixner, T., Sickman, J. O. and Melack, J. M. (2005) Episodic rewetting enhances carbon and nitrogen release from chaparral soils. Soil Biology and Biochemistry, 37, 2195-204.

Monson, R. K., Lipson, D. L., Burns, S. P. et al. (2006) Winter forest soil respiration controlled by climate and microbial community composition. Nature, $\mathbf{4 3 9}$, $711-14$

Nunan, N., Wu, K., Young, I. M., Crawford, J. W. and Ritz, K. (2002) In situ spatial patterns of soil bacterial populations, mapped at multiple scales, in an arable soil. Microbial Ecology, 44, 296-305.

Oorts, K., Bronckaers, H. and Smolders, E. (2006) Discrepancy of the microbial response to elevated copper between freshly spiked and long-term contaminated soils. Environmental Toxicology and Chemistrot, 25, 845-53.

Parkin, T. B. and Kaspar, T. C. (2004) Temporal variability of soil carbon dioxide flux: effect of sampling frequen on cumulative carbon loss estimation. Soil Science Society of America Journal, 68, 1234-41.

Person, T., Karlsson, P. S., Sjöberg, R. M. and Rudebeck, A. (2000) Carbon mincralization in European forest soils. Ecological Studies, 142, 257-75.

Prentice, I. C., Farquar, G. D. and Fasham, M. J. R. (2001) The carbon cycle and atmospheric carbon dioxide. In Climate Change 2001: The Scientific Basis. Contribution of Working Group I to the Third Assessment report of the Intergovernmental Panel on Climate Change. ambridge: Cambridge University Press, pp. 83-237. 
Pumpanen J Ilvesniemi, H., Peramaki, M. and Hari, P. (2003) Seasonal patterns of soil $\mathrm{CO}_{2}$ efflux and soil air $\mathrm{CO}_{2}$ concentration in a Scots pine forest: comparison two chamber techniques. Global Change Biology, 9 , $371-82$.

Raich, J. W. and Potter, C. S. (1995) Global patterns of carbon dioxide emissions from soils. Global Biogeachemical Cycles, 9, 23-36.

Raich, J.W. Potter, C S. and Bhagawati, D. (2002) Interannual variability in global soil respiration 1980-94. Global Change Biology, 8, 800-12.

Rajapaksha, R., Tobor-Kaplon, II. A. and Baath, E. (2004) Metal toxicity affects fungal and bacterial activities in soil differently. Applied and Environmental Microbiology, $70,2966-73$.

Rayment, M. B. and Jarvis, P. G. (2000) Temporal and spatial variation of soil $\mathrm{CO}_{2}$ efflux in a Canadian bore forest. Soil Biology and Biochemistry, 32, 35-45.

Reichstein, M., Rey, A., Freibauer, A. et al. (2003) Modeling temporal and large-scale spatial variability of soil respiration from soil water availability, temperature and vegetation productivity indices - art. no. 1104. Global Biogecuchemical Cycles, 17, 1104

Reichstein, M., Subke, J. A., Angeli, A. C. and Tenhunen, J. D. (2005) Does the temperature sensitivity of decomposition of soil organic matter depend upon water content, soil horizon, or incubation time? Global Change Biology', 11, 1754-67.

Reth, S., Reichstein, M. and Falge, E. (2005) The effect of soil water content, soil temperature, soil pH-value and the roor mass on soil $\mathrm{CO}_{3}$ effux: a modified model. the root mass on soil, 268, 21-33.

Savage, K. E. and Davidson, E. A. (2003) A comparison of manual and automated systems for soil $\mathrm{CO}_{2}$ flux measurements: trade-offs between spatial and temporal resolution. Fournal of Experimental Botany, 54, 891-9. Shaver, G. R., Giblin, A. E., Nadelhoffer, K. J. et al. (2006) Carbon turnover in Alaskan tundra soils: effects of organic matter quality, temperature, moisture and fertilizer. 7ournal of Ecology, 94, 740-53.

Sjoberg, G., Nilsson, S. I., Persson, T. and Karlsson, P. (2004) Degradation of hemicellulose, cellulose and lignin in decomposing spruce needle litter in relation to N. Soil Biology and Biochemistry, 36, 1761-8.

Smith, S. E. and Read, D. J. (1997) Mycorrhizal Symbiosis. London: Academic Press.

Smith, V. R. (2005) Moisture, carbon and inorganic nutrien controls of soil respiration at a sub-Antarctic island. Soil Biology and Biochemistry, 37, 81-91

Subke, J. A. and Tenhunen, J. D. (2004) Direct measurements of $\mathrm{CO}_{2}$ flux below a spruce forest canopy. Agricultural and Forest Meteorology, 126 $157-68$.

Subke, J. A., Reichstcin, M. and Tenhunen, J. (2003) Explaining temporal variation in soil $\mathrm{CO}_{2}$ efflux in a mature spruce forest in Southern Germany. Soil Biology' and Biochemistry, 35, 1467-83.

Suzuki, S., Ishizuka, S., Kitamura, K., Yamanoi, K. an Nakai, Y. (2006) Continuous estimation of winter carbon dioxide efflux from the snow surface in a deciduous broadleaf forest. Jnumal of Geophysical ResearchAtmuspheres, 111, D17101, doi 10.1029/2005JDoo6595.

Tang, J. W., Baldocchi, D. D., Qi, Y. and Xu, L. K. (2003) Assessing soil $\mathrm{CO}_{2}$ efflux using continuous measurements of $\mathrm{CO}_{2}$ profiles in soils with small solid-state sensors. Agricultural and Forest Meterorology, $118,207-20$

Tedeschi, V., Rey, A., Manca, G. et al. (2006) Soil respiration in a Mediterranean oak forest at different developmental stages after coppicing. Global Change Biology, 12, 110-21.

Wang, W. J., Zu, Y. G., Wang, H. M. et al. (2005) Effect of collar insertion on soil respiration in a larch forest measured with a $\mathrm{LL}-6400$ soil $\mathrm{CO}_{2}$ flux system. Journo of Forest Research, 10, 57-60.

Wilson, K. B and Ueyers, T. P. (2001) The spatial variability of energy and carbon dioxide fluxes at the floor of a deciduous forest. Boundary-Layer Meteorology, 98, 443-73.

Yim, M. H., Joo, S. J., Shutou, K. and Nakane, K. (2003) Spatial variability of soil respiration in a larch plantation: estimation of the number of sampling points required. Forest Ecology and Management, 175 $585-8$.

\section{Determination of soil carbon stocks and changes}

Mirco Rodeghiero, Andreas Heinemeyer, Marion Schrumpf and Pat Bellamy

4.1 INTRODUCTION

4.1.I Soil carbon pools and the global carbon cycle

In terrestrial ecosystems soils represent the major reservoir of organic carbon (Table 4.1), but with large and yet unquantified uncertainties in their estimates (mainly due to low soil sample numbers used for global upscaling and assumptions on mean soil depths). At the global level, the soil organic matter (SOM) pool (estimated to $1 \mathrm{~m}$ depth) contains about $1580 \mathrm{Pg}$ of carbon $\left(\mathrm{Pg}=10^{15} \mathrm{~g}\right)$, about $610 \mathrm{Pg}$ are stored in the vegetation and about $750 \mathrm{Pg}$ are present in the atmosphere (Schimel, 1995). Carbon is found in soils both in organic and inorganic forms (Table 4.2). Organic carbon is commonly classified into three 'arbitrary' pools, mostly for modelling purposes (such as in CENTURY) ie fast, how and pasive reflecting the rate of turyover. How-

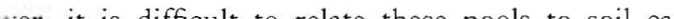
ene, it is differt to relate these pools to soil carbon fractions (see Section 4.1.5). The total amount of carbonate carbon to $1 \mathrm{~m}$ depth is estimated at 695$748 \mathrm{Pg}$ carbon (Batjes, 1996). About one third of organic soil carbon occurs in forests and another third in grasslands and savannas, the rest in wetlands, croplands and other biomes (Janzen, 2004). The global soil organic carbon map (Fig. 4.1, ISLSCP II; ORNL DAAC, http://daac.ornl.gov/) shows the areas of high soil organic carbon predominantly in cold boreal (e.g. Northern Canada) and warm and humid tropical regions (e.g. South-East Asia), reflecting areas of deep organic soils (i.e. peatlands). However, Fig. 4.1 also shows that even temperate zones, for example the United Kingdom, can contain considerable amounts of soil organic carbon in wet and cold upland regions.

Most of the soil organic carbon is not inert, but in a continuous dynamic state of accumulation and decomposition (Janzen, 2004; Schrumpf et al., 2008), the schematic soil carbon cycle in Fig. 4.2 indicates this continuous exchange of carbon between the sol and the atmosphere, mostly as carbon dioxide $\left(\mathrm{CO}_{2}\right)$ and methane $\left(\mathrm{CH}_{4}\right)$. Consequently, any net carbon los from soils will increase the $\mathrm{CO}_{2}$ concentration in the fmosphere and in water bodies, whereas net acer-

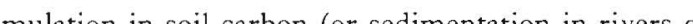
lakes etc) can contibute to the reduction of the a

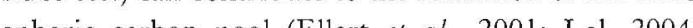
This cycling of carbon is increasingl infucnced by This cycling of carbon is increasingy influenced by haman activities (IPCC, 2007). On an annual basis,

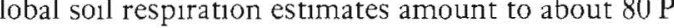
(Schlesinger and Andrews, 2000; Raich el al., 2002), roughly ten times the annual flux from fossi fuel combustion (7.2 Pg carbon; IPCC, 2007). Crucially, past and current cultivation of soils led to signifcant soil carbon losses of $50 \mathrm{Po}$ carbon or more (Janzen, 2006); corvely land-use or managne offer an oppory firy for sequestering a Don in sil (J 2006). Importy in term, these sil can term, these soil carbon changes can be greater than a key role in reducing atmospheric $\mathrm{CO}_{2}$ levels and their (e.g. climate change senarios) and political (e.g. Kyoto Protocol) analysis. Moreover, peatlands and other organic soils of cold and temperate regions are presently assumed to be a net sink of carbon but they might become a net carbo source $\left(\mathrm{CO}_{2}\right.$ a bu

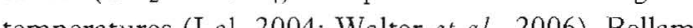
a at. (2005) and o happening.

As even small changes in soil organic carbon pools, due to climatic changes or to human activities, might have large impacts on the global carbon cycle (Garten 